\title{
Robust bifunctional oxygen electrocatalyst with a "rigid and flexible" structure for air-cathodes
}

\author{
Gengtao Fu $\mathbb{C}^{1,2}$, Xian Jiang ${ }^{1}$, Yifan Chen ${ }^{1}$, Lin Xu' ${ }^{1}$, Dongmei Sun ${ }^{1}$, Jong-Min Lee ${ }^{2}$ and Yawen Tang ${ }^{1}$
}

\begin{abstract}
The development of highly active air-cathodes with robust stability and a low price is of crucial significance for rechargeable $\mathrm{Zn}$-air batteries and remains a great challenge. Herein, for the first time, we report a "rigid and flexible" material consisting of three-dimensional (3D) porous nickel-manganese oxide $\left(\mathrm{Ni}_{6} \mathrm{MnO}_{8}\right)$ coupled with 1D ultrathin $\mathrm{Au}$ nanowires (Au-NWs) as an efficient bifunctional oxygen electrocatalyst, adopting a-naphthol-Au(III) as a precursor of Au-NWs and pre-formed $\mathrm{Ni}_{6} \mathrm{MnO}_{8}$ as a support. $\mathrm{Ni}_{6} \mathrm{MnO}_{8}$ acts not only as a robust carbon-free support that is stable in alkaline electrochemical conditions, but also as a highly active component for the oxygen evolution reaction (OER), while flexible Au-NWs contribute to the excellent oxygen reduction reaction (ORR) activity and act as a flexible conductive electronic network. The coupling of $\mathrm{Ni}_{6} \mathrm{MnO}_{8}$ and Au-NWs plays a complementary role in the two types of oxygen electrocatalytic reactions. Accordingly, their advantages have been optimally harnessed while overcoming their deficiencies. Moreover, a Zn-air battery assembled with such a rigid and flexible air-cathode has lower charge and discharge overpotentials and a higher cyclic stability than those with a mixed $\mathrm{Pt} / \mathrm{C}+\mathrm{RuO}_{2}$ catalyst.
\end{abstract}

\section{Introduction}

Oxygen-reduction and oxygen-evolution reactions (ORR and OER) are two significant reactions $\left(\mathrm{O}_{2}+2 \mathrm{H}_{2} \mathrm{O}+4 \mathrm{e}\right.$ $\leftrightarrow 4 \mathrm{OH}^{-}$), with oxygen reduced by electrons while discharging and the reverse process occurring during charging in rechargeable zinc $(\mathrm{Zn})$-air batteries, a promising technology to cope with future energy demands by virtue of their theoretically high energy density $\left(1084 \mathrm{Wh} \mathrm{kg}^{-1}\right)$, lowprice, eco-friendly nature, and safety ${ }^{1-10}$. However, $\mathrm{Zn}$-air batteries in practical energy devices remain less efficient in output and are unsatisfactorily stable in cycling resulting from the sluggish kinetics of oxygen reactions and the poor stability of catalysts at the air-cathode ${ }^{11-14}$. Additionally,

\footnotetext{
Correspondence: Jong-Min Lee (jmlee@ntu.edu.sg) or

Yawen Tang (tangyawen@njnu.edu.cn)

${ }^{1}$ Jiangsu Key Laboratory of New Power Batteries, Jiangsu Collaborative

Innovation Center of Biomedical Functional Materials, School of Chemistry and Materials Science, Nanjing Normal University, 210023 Nanjing, China

${ }^{2}$ School of Chemical and Biomedical Engineering, Nanyang Technological

University, Singapore 637459, Singapore

These authors contributed equally: Gengtao Fu, Xian Jiang
}

efficient bifunctional catalysts that are active for both ORRs and OERs is one of the great challenges faced in designing rechargeable $\mathrm{Zn}$-air batteries ${ }^{15-20}$. Thus far, the bestknown catalysts for oxygen electrocatalysis in alkaline media are prohibitive Pt-based metals for ORRs and Ir/Rubased metals for OERs ${ }^{21-23}$, but neither catalyst has sufficient bifunctional properties. Therefore, the development of highly active and stable bifunctional catalysts in light of lowprice transition metals is important for practically applying Zn-air batteries.

In contrast to all the other types of transition-metal alternatives, the oxides, encompassing perovskites (e.g., $\left.\mathrm{CaMnO}_{3}, \mathrm{LaMnO}_{3}\right)^{24}$, spinels (e.g., $\mathrm{CuCo}_{2} \mathrm{O}_{4}$, $\left.\mathrm{ZnCo}_{2} \mathrm{O}_{4}\right)^{25,26}$, pyrochlore oxides (e.g., $\mathrm{Pb}_{2} \mathrm{Ru}_{2} \mathrm{O}_{6.5}, \mathrm{Y}_{2}$ $\left.\left[\mathrm{Ru}_{2-x} \mathrm{Y}_{x}\right] \mathrm{O}_{7-y}\right)^{7,27}$, and oxysulfides (e.g., $\left.\mathrm{CoO}_{0.87} \mathrm{~S}_{0.13}\right)^{21}$, are potential bifunctional catalysts because of their chemical versatility and favorable stability in alkaline media. The electrocatalytic performances of metal oxides are limited by their intrinsically poor electrical conductivity, which can, however, be improved via supporting them on conductive

\section{(c) The Author(s) 2018}

(c) (i) Open Access This article is licensed under a Creative Commons Attribution 4.0 International License, which permits use, sharing, adaptation, distribution and reproduction c. in any medium or format, as long as you give appropriate credit to the original author(s) and the source, provide a link to the Creative Commons license, and indicate if changes were made. The images or other third party material in this article are included in the article's Creative Commons license, unless indicated otherwise in a credit line to the material. If material is not included in the article's Creative Commons license and your intended use is not permitted by statutory regulation or exceeds the permitted use, you will need to obtain permission directly from the copyright holder. To view a copy of this license, visit http://creativecommons.org/licenses/by/4.0/. 
materials. A synergetic combination of oxides with carbon materials is a general strategy for designing efficient bifunctional electrocatalysts ${ }^{28-35}$. Notably, such carbonsupported metal oxides are electrochemically unstable, especially under harsh OER conditions because carbon oxidation/corrosion occurs at relatively low potentials $\left(\mathrm{C}+2 \mathrm{H}_{2} \mathrm{O} \rightarrow \mathrm{CO}_{2}+4 \mathrm{H}^{+}+4 \mathrm{e}^{-}, E_{0}=0.207 \mathrm{~V}\right.$ vs. standard hydrogen potential $)^{36,37}$. Carbon corrosion has been identified as a main issue that greatly affects the stability of catalysts $^{11,38}$. In this regard, exploring robust carbon-free bifunctional electrocatalysts while retaining satisfactory electrical conductivity and evident catalytic activity is vitally necessary $^{36,38,39}$. For instance, Chen et al. developed a new carbon-free bifunctional catalyst comprising $\mathrm{CaMnO}_{3}$ and $\mathrm{Pt}$ clusters $\left(\mathrm{Pt} / \mathrm{CaMnO}_{3}\right)$ that exhibit evidently prolonged durability and optimized activity relative to that of carbonsupported $\mathrm{Pt}$ and $\mathrm{CaMnO}_{3}$ alone ${ }^{39}$. A similar result was also observed for a synergetic catalyst of $\mathrm{Co}_{3} \mathrm{O}_{4}$ and $\mathrm{Ag}$ particles $\left(\mathrm{Ag} / \mathrm{Co}_{3} \mathrm{O}_{4}\right)^{40}$. More recently, Goodenough et al. reported a robust $\mathrm{Ni}_{3} \mathrm{FeN}$-supported $\mathrm{Fe}_{3} \mathrm{Pt}\left(\mathrm{Fe}_{3} \mathrm{Pt} / \mathrm{Ni}_{3} \mathrm{FeN}\right)$ that can enable $\mathrm{Zn}$-air batteries to achieve long-term cycling stability with high efficiency as an air-cathode ${ }^{36}$. Although these robust carbon-free-supported noble metal catalysts become markedly more stable, the morphology and structure of these catalysts are unsatisfactory because electrocatalysis is a type of structure sensitive reaction, especially for ORRs.

Herein, a new, low-cost and highly active bifunctional electrocatalyst is designed and fabricated, consisting of flexible $\mathrm{Au}$ nanowires cross-linked with rigid $\mathrm{Ni}_{6} \mathrm{MnO}_{8}$ microspheres (Au-NWs $/ \mathrm{Ni}_{6} \mathrm{MnO}_{8}$ ) as an efficient aircathode. The $\mathrm{Ni}_{6} \mathrm{MnO}_{8}$ microspheres present a 3D hierarchically porous structure, while the Au nanowires have an ultrathin 1D anisotropic structure. Such "rigid and flexible" materials were prepared using in situ deposition of $\mathrm{Au}$ nanowires on the oxide support in the presence of $\alpha$-naphthol. Unlike the numerous Au nanowires previously reported, the Au-NWs outlined here can be rapidly synthesized with ultrathin diameters. Strongly coupled $\mathrm{Au}-\mathrm{NW} / \mathrm{Ni}_{6} \mathrm{MnO}_{8}$ have a superior bifunctional electrocatalytic performance, in which the Au-NWs are active for ORRs and $\mathrm{Ni}_{6} \mathrm{MnO}_{8}$ for OERs, coinciding with the concept of "rigid and flexible coupling". Meanwhile, $\mathrm{Au}-\mathrm{NWs} / \mathrm{Ni}_{6} \mathrm{MnO}_{8}$ is electrochemically stable over the potential range of an air-cathode in an alkaline medium. The synergistic interaction of the 3D porous structure and the metallic 1D nanowires provides abundant catalytic active sites and facilitates mass and electron transport. Moreover, a $\mathrm{Zn}$-air battery adopting Au-NWs/ $\mathrm{Ni}_{6} \mathrm{MnO}_{8}$ as the air-cathode exhibits a larger peak power density $\left(118 \mathrm{~mW} \mathrm{~cm}^{-2}\right)$, a higher specific capacity $\left(768 \mathrm{mAh}_{\mathrm{Zn}}{ }^{-1}\right)$ and a longer cycle life than that of a mixed $\mathrm{Pt} / \mathrm{C}+\mathrm{RuO}_{2}$ air-cathode. This paper is the first to report the synthesis of rigid $\mathrm{Ni}_{6} \mathrm{MnO}_{8}$-supported flexible
$\mathrm{Au}$ nanowires as an efficient synergistic catalyst for aircathode reactions.

\section{Materials and methods \\ Materials}

Nickel (II) nitrate hexahydrate $\left(\mathrm{Ni}\left(\mathrm{NO}_{3}\right)_{2} \cdot 6 \mathrm{H}_{2} \mathrm{O}\right)$, manganese (II) acetate tetrahydrate $\left(\mathrm{Mn}(\mathrm{COOH})_{2} \cdot 4 \mathrm{H}_{2} \mathrm{O}\right)$, and hydrogen tetrachloroaurate (III) tetrahydrate $\left(\mathrm{HAuCl}_{4} \cdot 4 \mathrm{H}_{2} \mathrm{O}\right)$ were purchased from Alfa Aesar. Hexamethylenetetramine (HMTA), $\alpha$-naphthol $\left(\mathrm{C}_{10} \mathrm{H}_{8} \mathrm{O}\right)$, and ruthenium oxide $\left(\mathrm{RuO}_{2}\right)$ were supplied by Aladdin. Commercial $\mathrm{Pt} / \mathrm{C}$ was purchased from Johnson Matthey Chemicals Ltd. All reagents and chemicals were used without further purification.

\section{Synthesis of $\mathrm{Ni}_{6} \mathrm{MnO}_{8}$ samples}

Typically, $\mathrm{Ni}\left(\mathrm{NO}_{3}\right)_{2}$ and $\mathrm{Mn}(\mathrm{COOH})_{2}$ in a 3:1 molar ratio was dissolved into $20 \mathrm{~mL}$ of deionized water (metalion concentration $40 \mathrm{mM}$ ) with $560 \mathrm{mg}$ of HMTA by continuously stirring. The mixture was then transferred to a Teflon-lined steel autoclave and heated in an oven at $80^{\circ} \mathrm{C}$ for $12 \mathrm{~h}$. Once cooled to room temperature, the obtained precipitate was collected and washed several times with deionized water and subsequently dried at $60^{\circ} \mathrm{C}$ to yield the hierarchical NiMn LDHs. Then, the resulting NiMn LDHs were placed in a tube furnace and annealed in air at $600^{\circ} \mathrm{C}$ for $4 \mathrm{~h}$ at a heating rate of $5^{\circ} \mathrm{C} \mathrm{min}^{-1}$. After natural cooling to room temperature, the porous $\mathrm{Ni}_{6} \mathrm{MnO}_{8}$ hierarchical microspheres were collected.

\section{Synthesis of Au-NWs $/ \mathrm{Ni}_{6} \mathrm{MnO}_{8}$ and $\mathrm{Au}-\mathrm{NWs} / \mathrm{C}$ samples}

Typically, $25 \mathrm{mg}$ of $\mathrm{Ni}_{6} \mathrm{MnO}_{8}$ powder (or carbon black) was added into a $10 \mathrm{~mL}$ mixture of deionized water and ethanol $\left(V_{\text {water }}: V_{\text {ethanol }}=1: 1\right)$ with $144 \mathrm{mg}(1 \mathrm{mM})$ of $\alpha$ naphthol in an ultrasonic bath for $10 \mathrm{~min}$ to form a uniform solution. Then, $2.0 \mathrm{~mL}$ of $0.05 \mathrm{M} \mathrm{HAuCl}_{4}$ solution was added into the above mixture and further stirred for $10 \mathrm{~min}$. Finally, the mixture was treated by submersion in a water bath at $60^{\circ} \mathrm{C}$ for a few minutes. The resulting Au$\mathrm{NWs} / \mathrm{Ni}_{6} \mathrm{MnO}_{8}$ and $\mathrm{Au}-\mathrm{NW} / \mathrm{C}$ catalysts were then centrifuged and extensively washed with deionized water.

\section{Synthesis of pure Au-NWs and Au-particles $/ \mathrm{Ni}_{6} \mathrm{MnO}_{8}$ samples}

Pure Au-NWs were prepared using an ultrafast method. Specifically, $2.0 \mathrm{~mL}$ of $0.05 \mathrm{M} \mathrm{HAuCl}_{4}$ solution was added into a mixture of $5 \mathrm{~mL}$ of deionized water and $5 \mathrm{~mL}$ of ethanol with $1 \mathrm{mM}$ alpha naphthol in an ultrasonic bath for $10 \mathrm{~min}$ to form a uniform solution, followed by submersion in a water bath at $60^{\circ} \mathrm{C}$ for a few minutes. For the synthesis of the Au-particles/ $\mathrm{Ni}_{6} \mathrm{MnO}_{8}$ catalyst, $\mathrm{Au}$ colloids were first synthesized in a trisodium citrate solution: a $20 \mathrm{~mL}$ mixed solution containing $0.10 \mathrm{mM} \mathrm{HAuCl}_{4}$ and 
$0.25 \mathrm{mM}$ trisodium citrate was prepared at room temperature, and $\mathrm{NaBH}_{4}$ was also dissolved in deionized water; the resulting solution $(0.01 \mathrm{M})$ was used as a reducing agent; with the dropwise addition of $0.5 \mathrm{~mL}$ of the $\mathrm{NaBH}_{4}$ solution, the red-wine solution containing $\mathrm{Au}$ colloids was formed. Then, an appropriate aliquot of $\mathrm{Au}$ colloids was mixed with $\mathrm{Ni}_{6} \mathrm{MnO}_{8}$ in a beaker while being vigorously stirred for $30 \mathrm{~min}$, resulting in the deposition of $\mathrm{Au}$ colloids on the $\mathrm{Ni}_{6} \mathrm{MnO}_{8}$ supports. Finally, the $\mathrm{Au}$ particles $/ \mathrm{Ni}_{6} \mathrm{MnO}_{8}$ catalyst was obtained by filtration and washing with water to remove excess surfactant and reducing agent.

\section{Physicochemical characterization}

The phase purity and crystallinity of the products were identified using X-ray powder diffraction (XRD) on a Rigak Smartlab X-ray with $\mathrm{Cu}-\mathrm{K} \alpha$ radiation $(\lambda=$ $0.1541 \mathrm{~nm}$ ). Scanning electron microscopy (SEM) and energy-dispersive X-ray analysis (EDX) were performed using a Hitachi S4800 SEM. Transmission electron microscopy (TEM) and scanning transmission electron microscopy (STEM) were performed using a JEOL 2010F TEM/STEM operated at $200 \mathrm{kV}$. X-ray photoelectron spectroscopy (XPS) was performed using a Thermo VG Scientific ESCALAB 250 spectrometer with an $\mathrm{Al}-\mathrm{K} \alpha$ radiator. The binding energy (BE) was calibrated using the $C$ 1s peak energy of $284.6 \mathrm{eV}$. The Brunauer-Emmett-Teller (BET)-specific surface area was measured at $77 \mathrm{~K}$ using a Micromeritics ASAP 2050 system. The electrical conductivity was measured using 4-probe conductivity measurements on an ST-2722 semiconductor resistivity of the powder tester (Suzhou Jingge Electronic Co., Ltd., China) under a pressure of $10 \mathrm{MPa}$.

\section{Electrochemical measurements}

Electrochemical measurements were carried out using a CHI 760E electrochemical analyzer (Shanghai, Chenghua Co.). A standard three-electrode system was used, including a rotating disk electrode (RDE) or rotating ring-disk electrode (RRDE) as the working electrodes $\left(0.196 \mathrm{~cm}^{2}\right)$, a platinum wire as the auxiliary electrode, and a saturated calomel electrode protected by a Luggin capillary with $\mathrm{KCl}$ solution as the reference electrode. The catalyst ink was prepared by ultrasonically dispersing the mixture of $5 \mathrm{mg}$ of catalyst, $1 \mathrm{~mL}$ of ethanol, and $20 \mu \mathrm{L}$ of 5 wt.\% Nafion solution; $10 \mu \mathrm{L}$ of the catalyst ink was pipetted and spread onto the electrode. The loading of the studied catalysts was $250 \mu \mathrm{g} \mathrm{cm}^{-2}$. For the ORR test, the background current was measured under a $\mathrm{N}_{2}$ atmosphere at an identical rotation speed and scan rate as for measurements conducted under $\mathrm{O}_{2}$. The ORR activities of the catalysts were measured via the RRDE voltammograms in $0.1 \mathrm{M} \mathrm{KOH}$ electrolyte at the predefined rotation rate of $1600 \mathrm{rpm}$ and a scan rate of $5 \mathrm{mV} \mathrm{s}^{-1}$. Before testing, $\mathrm{O}_{2}$ was passed through the electrolyte for at least $20 \mathrm{~min}$ to saturate the electrolyte with $\mathrm{O}_{2}$. To remove the capacitive current of the working electrode, the background current was measured by running the above electrodes in $\mathrm{N}_{2}$-saturated $0.1 \mathrm{M} \mathrm{KOH}$ and then was subtracted from the ORR polarization curve. The percentage of $\mathrm{HO}_{2}^{-}$intermediate production (\% $\left.\mathrm{HO}_{2}{ }^{-}\right)$and electron transfer number $(n)$ were determined using the following equations:

$$
\% H O_{2}^{-}=\frac{200 I_{r}}{N I_{d}+I_{r}} \quad n=\frac{4 N I_{d}}{N I_{d}+I_{r}},
$$

where $I_{\mathrm{d}}$ is the disk current, $I_{\mathrm{r}}$ is the ring current, and $N$ is the current collection efficiency of the Pt ring, which was determined to be 0.37 . For the OERs, the polarization curves were also measured in $0.1 \mathrm{M} \mathrm{KOH}$ solution recorded from 1.1 to $2.0 \mathrm{~V}$ at a scan rate of $5 \mathrm{mV} \mathrm{s}^{-1}$. Note that high-purity $\mathrm{O}_{2}$ is bubbled through the electrolyte during testing to fix the reversible oxygen potential (or ensure the $\mathrm{O}_{2} / \mathrm{H}_{2} \mathrm{O}$ equilibrium at $1.23 \mathrm{~V}$ vs. RHE). To avoid the peeling of the catalyst that is caused by evolved $\mathrm{O}_{2}$ adhesion, a rotation speed of $1600 \mathrm{rpm}$ was used during the OERs.

The $\mathrm{Zn}$-air battery tests were performed with a homemade Zn-air cell. The air-cathode consisted of hydroholic carbon paper with a gas diffusion layer on the air-facing side and a catalyst layer on the water-facing side. The catalyst layer was made by loading catalyst ink onto the carbon paper by drop-casting, with a loading of $10 \mathrm{mg} \mathrm{cm}^{-2}$ for all the catalysts. A polished $\mathrm{Zn}$ plate with a thickness of $0.3 \mathrm{~mm}$ was used as the anode. A $0.2 \mathrm{M}$ $\mathrm{ZnCl}_{2}+6 \mathrm{M} \mathrm{KOH}$ mixed solution was used as the electrolyte. The gas diffusion layer had an effective area of $0.5 \mathrm{~cm}^{2}$ and allows $\mathrm{O}_{2}$ from the ambient air to reach the catalyst sites. A Land CT2001A system was used to perform the cycling test with a 5-min rest time between each discharge and charge at a current density of $10 \mathrm{~mA} \mathrm{~cm}^{-2}$. Each discharge and charge period was set to be $20 \mathrm{~min}$.

\section{Results}

\section{Structure and composition of Au-NWs $/ \mathrm{Ni}_{6} \mathrm{MnO}_{8}$}

Figure 1a presents a schematic diagram for the fabrication process of the $\mathrm{Au}-\mathrm{NW} / \mathrm{Ni}_{6} \mathrm{MnO}_{8}$ catalyst, which primarily involves three steps: (i) co-deposition of $\mathrm{Ni}$ and Mn precursors to form hierarchical NiMn layered double hydroxides (NiMn LDHs) with the aid of HMTA, in which HMTA was used as a hydrolysis agent to slowly alkalize the solution and homogeneously precipitate out bimetallic NiMn LDHs; (ii) pyrolysis treatment at $600^{\circ} \mathrm{C}$ in air to promote the formation of the hierarchically porous $\mathrm{Ni}_{6} \mathrm{MnO}_{8}$ phase; (iii) and ultrafast in situ growth of $\mathrm{Au}$ nanowires on the oxide support via a novel and simple water bath method in the presence of $\alpha$-naphthol. 
The experimental details are provided in the experimental section. The XRD pattern of NiMn LDHs (Fig. S1) shows diffraction peaks at $2 \theta$ of $9.5,19.0,34.7,38.7,44.6$, and 60.0, which can be, respectively, indexed to (003), (006), (012), (015), (018), and (110) reflections of the rhombohedral LDH phase. Figure $1 \mathrm{~b}$ shows the XRD patterns of the $\mathrm{Au}-\mathrm{NW}, \mathrm{Ni}_{6} \mathrm{MnO}_{8}$, and $\mathrm{Au}-\mathrm{NW} / \mathrm{Ni}_{6} \mathrm{MnO}_{8}$ samples. As observed, all of diffraction peaks for the obtained oxide support are observed to be well geared into the facecentered cubic (fcc) murdochite-type $\mathrm{Ni}_{6} \mathrm{MnO}_{8}$ rigid structure (space group: Fm3m (225), JCPDS No. 83-1186, $\mathrm{a}=\mathrm{b}=\mathrm{c}=8.32 \AA$ ). No other crystalline phase was detected, which indicates that the final product has a high purity. Murdochite-type $\mathrm{Ni}_{6} \mathrm{MnO}_{8}$ has a derived rock-salt structure, and one-eighth of the $\mathrm{Ni}^{2+}$ ions are replaced by $\mathrm{Mn}^{4+}$ ions and vacancies (Fig. 1c and Fig. S2) ${ }^{41,42}$. This murdochite-type rigid structure was found to be chemically stable after being soaked in $0.1 \mathrm{M} \mathrm{KOH}$ solution for 2 weeks, as demonstrated by the XRD patterns (Fig. S3). There are five additional diffraction peaks of the $\mathrm{Au}$ $\mathrm{NWs} / \mathrm{Ni}_{6} \mathrm{MnO}_{8}$ hybrid appearing at $38.3^{\circ}, 44.5^{\circ}, 64.7^{\circ}$, $77.7^{\circ}$, and $81.9^{\circ}$ as compared to $\mathrm{Ni}_{6} \mathrm{MnO}_{8}$; they are consistent with the (111), (200), (220), (311), and (222) reflections of fcc $\mathrm{Au}$ (space group: Fm3m (225), JCPDS No. 65-8601, $\mathrm{a}=\mathrm{b}=\mathrm{c}=4.072 \AA)$. The XRD results indicate the successful reduction of the $\mathrm{Au}(\mathrm{III})$ precursor with $\alpha$-naphthol as the reducing agent.

Micro/nanostructures of the as-synthesized NiMn LDHs, $\mathrm{Ni}_{6} \mathrm{MnO}_{8}$, and $\mathrm{Au}-\mathrm{NW} / \mathrm{Ni}_{6} \mathrm{MnO}_{8}$ were characterized specifically using electron microscopy technology. Representative SEM images (Fig. 2a and Fig. S4) of the NiMn LDHs display a 3D hierarchical porous architecture comprising dozens of interconnected sheet-like subunits. After thermal pyrolysis, the $\mathrm{Ni}_{6} \mathrm{MnO}_{8}$ sample retains the structure and morphology integrity of the hierarchical NiMn LDH microspheres, while the sheet-like subunits of the NiMn LDHs were completely transformed into porous ones (Fig. $2 \mathrm{~b}$ and Fig. S5). The porous subunits packed with particles make the surface much coarser (Fig. S5), hinting at open and accessible mesopore channels, which should provide open pathways for mass transportation ${ }^{43,44}$. Figure $2 \mathrm{c}$ and $\mathrm{d}$ and Fig. S6 display SEM images of Au-NWs $/ \mathrm{Ni}_{6} \mathrm{MnO}_{8}$. After the decorating of $\mathrm{Au}$ nanowires, the $\mathrm{Au}-\mathrm{NW} / \mathrm{Ni}_{6} \mathrm{MnO}_{8}$ sample manifests a 3D interconnected architecture akin to the original $\mathrm{Ni}_{6} \mathrm{MnO}_{8}$ oxides. Remarkably, the randomly tortuous $\mathrm{Au}$ nanowires are uniformly dispersed on the surface of the oxides, filling the pores and bridging the boundary of the porous sheet-like subunits. The flexible Au nanowires can work conductive bridges to offer effective electron transport channels. Although $\mathrm{Ni}_{6} \mathrm{MnO}_{8}$ itself has a poor

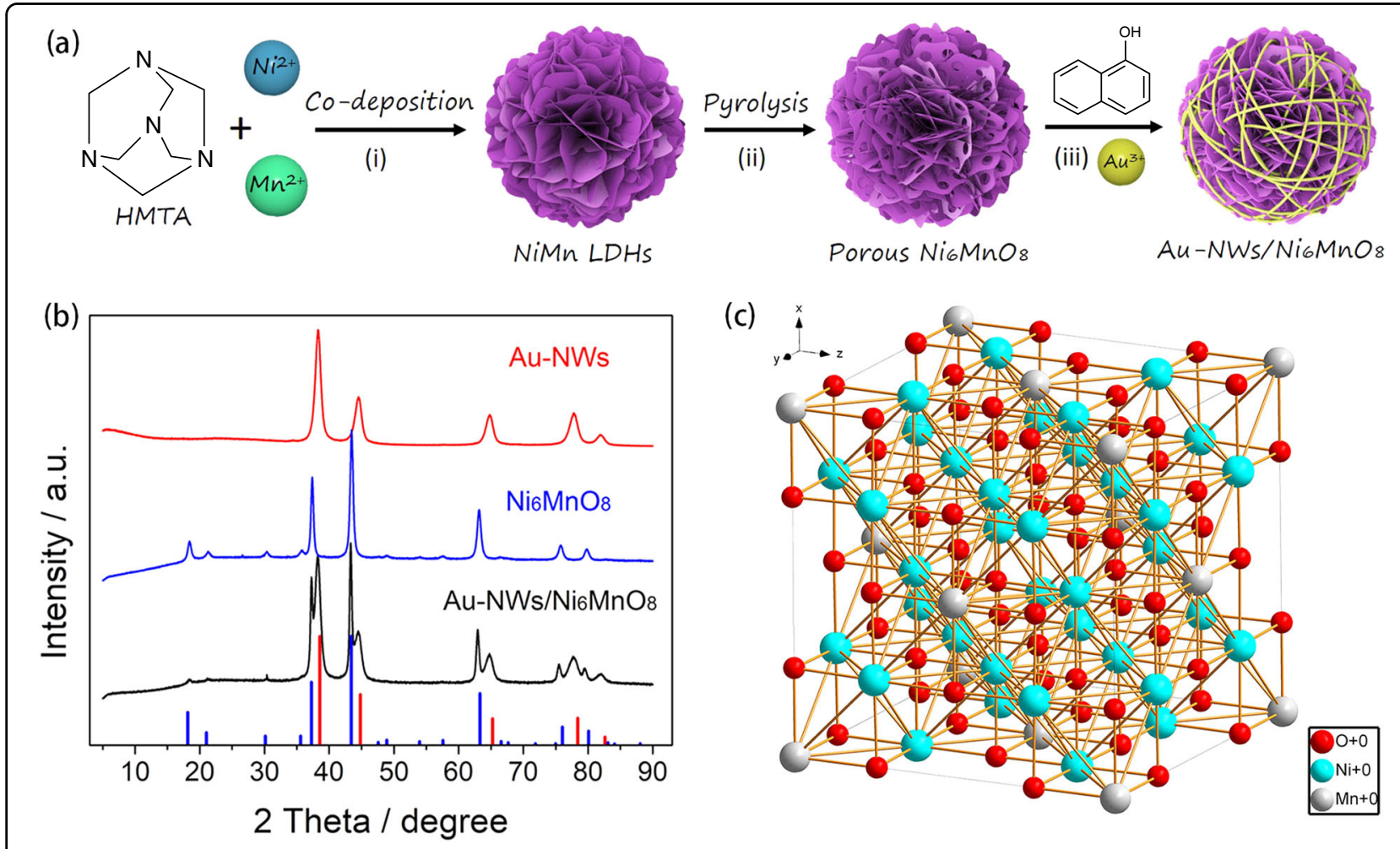

Fig. 1 a Schematic illustration of the formation of the Au-NWs $/ \mathrm{Ni}_{6} \mathrm{MnO}_{8}$ catalyst; $\mathbf{b}$ XRD patterns of the $\mathrm{Au}-\mathrm{NW}, \mathrm{Ni}_{6} \mathrm{MnO}_{8}$, and $\mathrm{Au}_{\mathrm{N}} \mathrm{NWs} / \mathrm{Ni}_{6} \mathrm{MnO} \mathrm{O}_{8}$ samples, drop lines corresponding to $\mathrm{Ni}_{6} \mathrm{MnO}_{8}$ (JCPDS No. 83-1186) and $\mathrm{Au}$ (JCPDS No. 65-8601); $\mathbf{c}$ the crystal structure of the $\mathrm{Ni}_{6} \mathrm{MnO}_{8}$ phase 
conductivity $\left(2.46 \times 10^{-3} \mathrm{~S} \mathrm{~m}^{-1}\right)$, the $\mathrm{Au}-\mathrm{NWs} / \mathrm{Ni}_{6} \mathrm{MnO}_{8}$ hybrid demonstrates a better electrical conductivity of approximately $1.25 \times 10^{3} \mathrm{~S} \mathrm{~m}^{-1}$ that can facilitate electron transport during electrocatalysis. To better investigate the structural features of Au-NWs $/ \mathrm{Ni}_{6} \mathrm{MnO}_{8}$, TEM measurements were conducted, as presented in Fig. $2 \mathrm{e}$ and $\mathrm{f}$ and Fig. S7. Flexible nanowires with a high morphological yield (100\%) and an ultrathin diameter of approximately $4 \mathrm{~nm}$ (Fig. S6d) were observed on the $\mathrm{Ni}_{6} \mathrm{MnO}_{8}$ surface. The highresolution TEM (HRTEM) image and the corresponding fast Fourier transform (FFT) patterns show two types of crystalline domains of $\mathrm{Au}$ and $\mathrm{Ni}_{6} \mathrm{MnO}_{8}$ oriented along the [110] and [100] zone axes (Fig. 2g), respectively. The EDX elemental mappings (Fig. 2i and Fig. S8) reveal a uniform distribution of Ni, Mn, O, and Au in the STEM image (Fig. 2h), which demonstrates the homogeneous growth of Au nanowires on the porous $\mathrm{Ni}_{6} \mathrm{MnO}_{8}$ surface. The content of $\mathrm{Au}$ in the $\mathrm{Au}-\mathrm{NW} / \mathrm{Ni}_{6} \mathrm{MnO}_{8}$ is approximately $22 \mathrm{wt} . \%$, which was demonstrated by the EDX spectrum (Fig. S9).

A nitrogen adsorption-desorption measurement was performed to ascertain the porosity of $\mathrm{Au}-\mathrm{NWs} /$
$\mathrm{Ni}_{6} \mathrm{MnO}_{8}$. The adsorption-desorption curves (Fig. 3a) manifest representative type-IV isotherms with a distinctive hysteresis loop, which indicates the existence of microporous/mesoporous structures. The BET-specific surface area was calculated to be approximately $176 \mathrm{~m}^{2} \mathrm{~g}^{-1}$. The surface state of the $\mathrm{Au}$ nanowires and $\mathrm{Ni}_{6} \mathrm{MnO}_{8}$ and the interaction between them were ascertained using XPS. The full XPS spectrum clearly indicates the co-existence of $\mathrm{Au}, \mathrm{Mn}, \mathrm{Ni}$, and $\mathrm{O}$ elements in the $\mathrm{Au}-\mathrm{NWs} / \mathrm{Ni}_{6} \mathrm{MnO}_{8}$ hybrid (Fig. S10). Figure $3 \mathrm{~b}$ shows the high-resolution Au4f spectrum of $\mathrm{Au}-\mathrm{NWs} / \mathrm{Ni}_{6} \mathrm{MnO}_{8}$. The Au4f peaks centered at 83.7 and $87.4 \mathrm{eV}$ are assigned to the spin-orbit doublet characteristic of metallic Au. Note that the Au4f peaks for $\mathrm{Au}-\mathrm{NW} / \mathrm{Ni}_{6} \mathrm{MnO}_{8}$ shifted to a lower $\mathrm{BE}$ by $0.48 \mathrm{eV}$ in contrast to that of the non-supported $\mathrm{Au}$ nanowires, which was prepared via the direct $\alpha$-naphthol reduction method (see Experimental for details). Given the similar morphology and surface properties of the $\mathrm{Au}$ particles in $\mathrm{Au}-\mathrm{NW} / \mathrm{Ni}_{6} \mathrm{MnO}_{8}$ and non-supported $\mathrm{Au}-\mathrm{NWs}$ (Fig. S11), the Au4f-BE shift of Au-NWs/ $\mathrm{Ni}_{6} \mathrm{MnO}_{8}$ probably arose from the strong incorporation
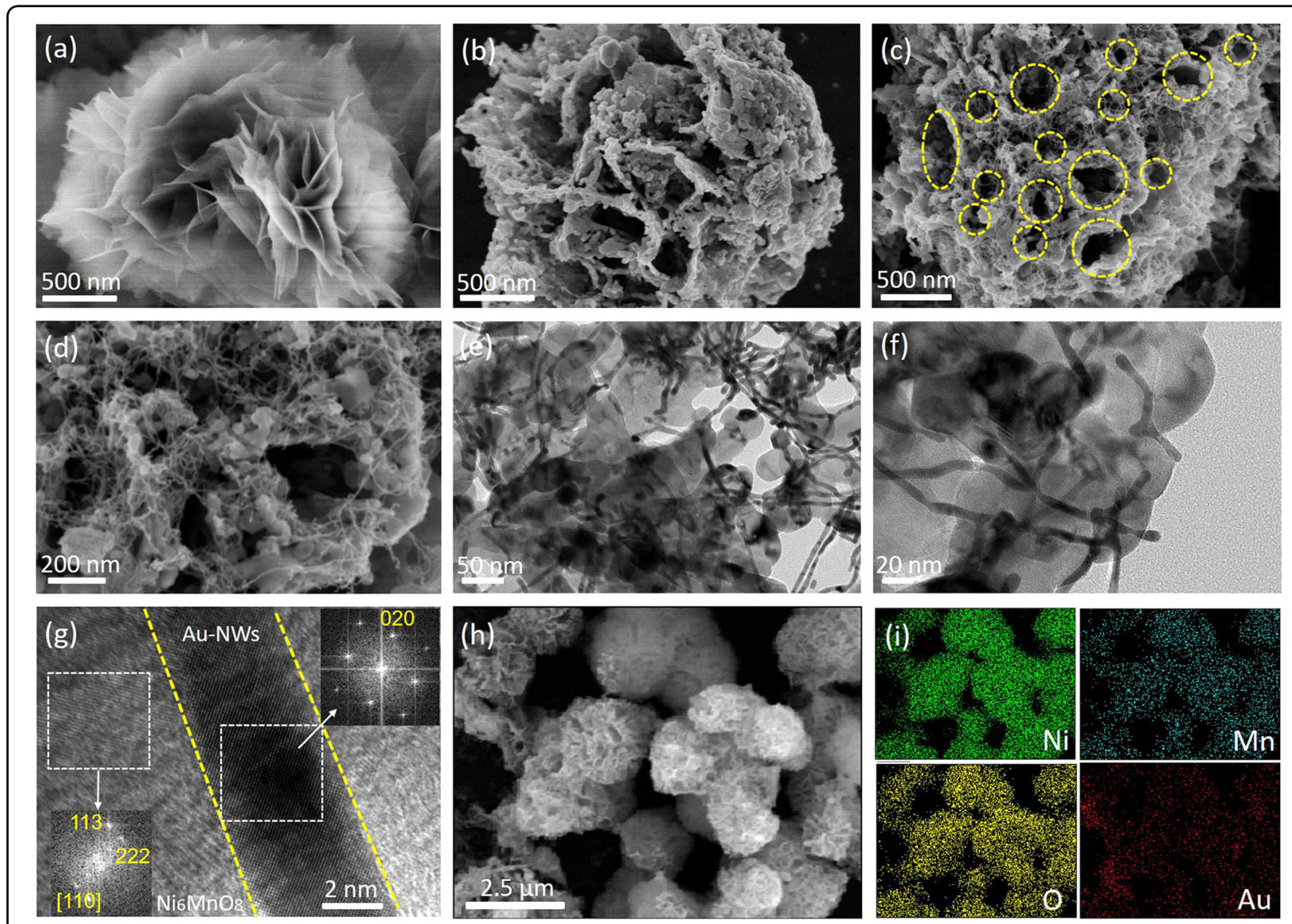

Fig. 2 SEM images of a NiMn LDHs microspheres; $\mathbf{b} ~ \mathrm{Ni}_{6} \mathrm{MnO}_{8}$ microspheres; $\mathbf{c}$, $\mathbf{d}$ Au-NWs $/ \mathrm{Ni}_{6} \mathrm{MnO}_{8} ; \mathbf{e}, \mathbf{f} \mathrm{TEM}$ images of $\mathrm{Au}-\mathrm{NWs} / \mathrm{Ni} \mathrm{MnOO}_{8} ; \mathbf{g} \mathrm{HRTEM}$ image of $\mathrm{Au}-\mathrm{NWs} / \mathrm{Ni}_{6} \mathrm{MnO}_{8}$ and the corresponding FFT patterns from the selected region of $\mathrm{Ni}_{6} \mathrm{MnO}_{8}$ and Au-NWs; $\mathbf{h}$ STEM image of Au-NWs/ $\mathrm{Ni}_{6} \mathrm{MnO}_{8}$; and $\mathbf{i}$ the corresponding EDX element mappings 
between the oxide support and Au nanowires. The XPS analysis of the $\mathrm{Au}-\mathrm{NW} / \mathrm{Ni}_{6} \mathrm{MnO}_{8}$ also demonstrated that $\mathrm{Ni}$ (II) and Mn (IV) are the dominant species in the $\mathrm{Ni}_{6} \mathrm{MnO}_{8}$ (Fig. 3c, d). Additionally, a definite positive shift was found in the $\mathrm{BE}$ of the Ni2p and Mn2p peaks, for $\mathrm{Au}-$ $\mathrm{NWs} / \mathrm{Ni}_{6} \mathrm{MnO}_{8}$ relative to $\mathrm{Au}$-free $\mathrm{Ni}_{6} \mathrm{MnO}_{8}$. The positive shifts in the $\mathrm{BE}$ of the Ni2p and Mn2p peaks further demonstrate the presence of electron interactions between $\mathrm{Au}$ and $\mathrm{Ni}_{6} \mathrm{MnO}_{8}$ in $\mathrm{Au}-\mathrm{NWs} / \mathrm{Ni}_{6} \mathrm{MnO}_{8}$, consequently transferring electrons from $\mathrm{Ni}_{6} \mathrm{MnO}_{8}$ to metallic Au. Note that $\alpha$-naphthol has little influence on the valence state of $\mathrm{Ni}_{6} \mathrm{MnO}_{8}$ because of its low reducing capacity. In contrast with numerous $\mathrm{Au}$ nanowires that have been reported previously, the Au-NWs outlined here have better structural advantages, and the $\alpha$-naphtholdriven synthetic method is deemed to be more rapid and effective. Detailed comparisons are provided in Table S1. Notably, $\alpha$-naphthol is critically significant in the formation of $\mathrm{Au}$ nanowires. In the absence of $\alpha$-naphthol, the $\mathrm{HAuCl}_{4}$ precursor cannot be reduced under the present $\mathrm{HAuCl}_{4}-\alpha$-naphthol- $\mathrm{Ni}_{6} \mathrm{MnO}_{8}$ conditions, while in the presence of $\alpha$-naphthol and without adding $\mathrm{Ni}_{6} \mathrm{MnO}_{8}$, pure $\mathrm{Au}$ nanowires also can obtained rapidly. Accordingly, $\alpha$-naphthol is deduced to be able to not only serve as a reducing agent but also direct the formation of ultrathin Au nanowires. To confirm the rapid formation of $\mathrm{Au}$ nanowires, the reaction process was continuously monitored using UV-Vis spectroscopy at the surface plasmon resonance (SPR) peak of the $\mathrm{Au}$ particles (approximately $550 \mathrm{~nm}$ ). As Fig. 3e indicates, the intensity of the SPR peak progressively increases as the reaction progress until equilibrium occurs. The acquisition of the equilibrium point indicates the end of the reduction reaction. We found that it merely takes $130 \mathrm{~s}$ to completely reduce the $\mathrm{HAuCl}_{4}$ precursor under the present reaction conditions. This phenomenon might stem from the strong molecular interaction between $\alpha$-naphthol and $\mathrm{HAuCl}_{4}$ that was ascertained from the UV-Vis spectra (Fig. 3f). When $\alpha$-naphthol was incorporated into the $\mathrm{HAuCl}_{4}$ solution, the characteristic absorption peak at $317 \mathrm{~nm}$ of the $\mathrm{HAuCl}_{4}$ species is markedly blue-shifted. Moreover, as the nanowires were directed by $\alpha$-naphthol$\mathrm{Au}(\mathrm{III})$, due to the sufficient pre-interaction between $\alpha$ naphthol and $\mathrm{Ni}_{6} \mathrm{MnO}_{8}$ support through the electrostatic binding, the Au nanowires capped by $\alpha$-naphthol had the opportunity to come into intimate contact with the oxide support, resulting in the in situ deposition of the $\mathrm{Au}$ nanowires onto the $\mathrm{Ni}_{6} \mathrm{MnO}_{8}$.

\section{Bifunctional electrocatalytic activities for the OERs and ORRs}

Given the unique structural advantages of the Au-NWs/ $\mathrm{Ni}_{6} \mathrm{MnO}_{8}$ hybrid, that is, inclusive of numerous mesopores, high BET surface area, and prominent electrical
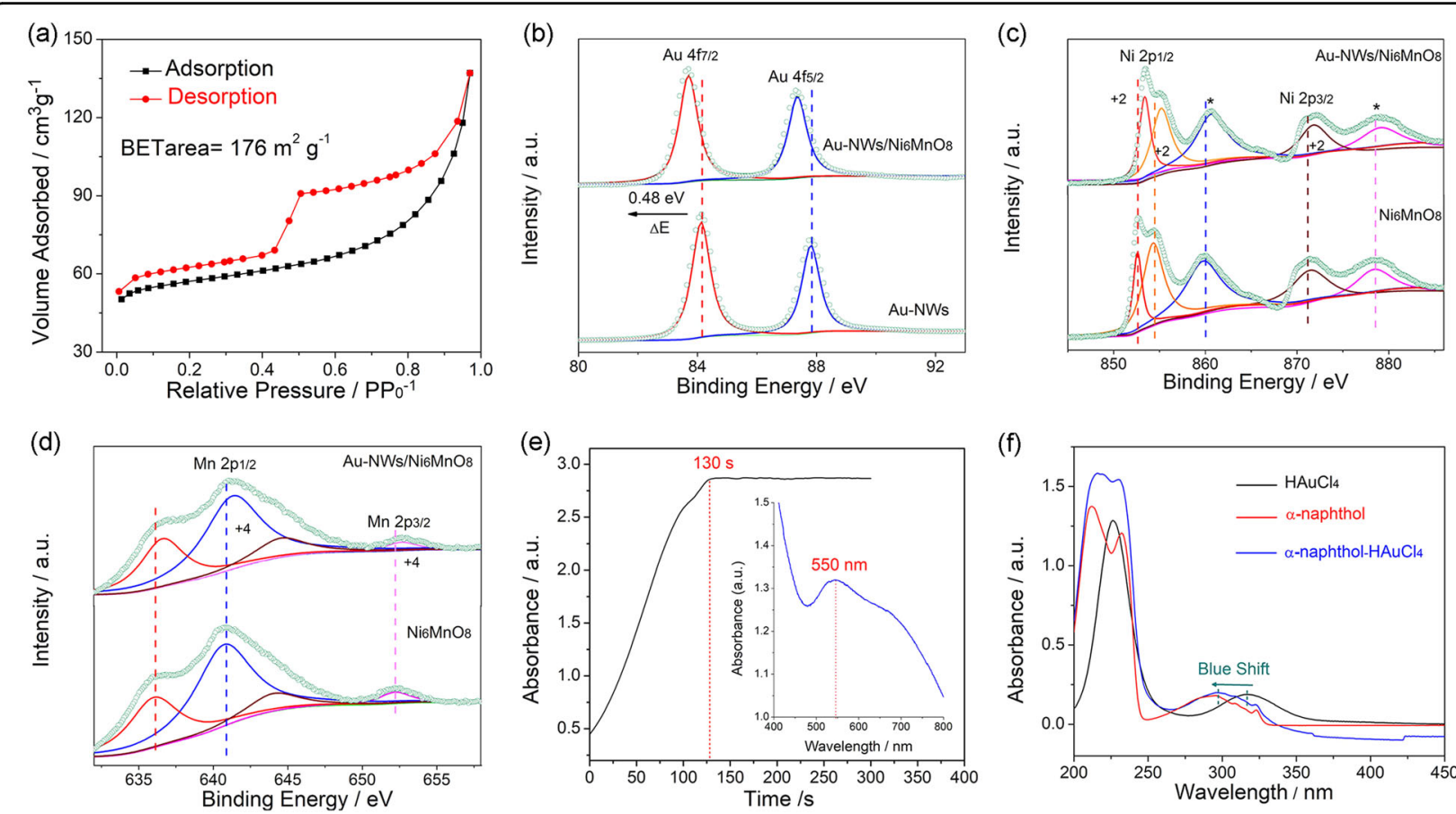

Fig. 3 a $\mathrm{N}_{2}$ adsorption-desorption isotherms of Au-NWs/Ni $\mathrm{MnO}_{8}$ microspheres; b high-resolution Au4f, c Ni2p, and $\mathbf{d}$ Mn $2 p$ XPS spectra of Au$\mathrm{NWs} / \mathrm{Ni}_{6} \mathrm{MnO}_{8}$ and Au-NWs; e the intensity of SPR peak changes as a function of time, the inset is the UV-Vis spectrum of a Au nanowire after a complete reaction; $\mathbf{f} U V$-Vis spectra of $\mathrm{HAuCl}_{4}$, a-naphthol, and a-naphthol-HAuCl${ }_{4}$ complex solutions 
conductivity, they should be very promising for electrocatalysis. First, the ORR activity of $\mathrm{Au}-\mathrm{NWs} / \mathrm{Ni}_{6} \mathrm{MnO}_{8}$ (Fig. 4a) was evaluated using a RDE. The performances of the $\mathrm{Ni}_{6} \mathrm{MnO}_{8}$ and $\mathrm{Au}-\mathrm{NWs}$ samples are provided for comparison. Au-NWs $/ \mathrm{Ni}_{6} \mathrm{MnO}_{8}$ shows significantly improved ORR activity in terms of its more positive halfpotential $\left(E_{1 / 2}=0.90 \mathrm{~V}\right)$ as compared with Au-NWs $(0.88 \mathrm{~V})$ and $\mathrm{Ni}_{6} \mathrm{MnO}_{8}(0.62 \mathrm{~V})$, suggesting that oxygen was more easily reduced on the $\mathrm{Au}-\mathrm{NWs} / \mathrm{Ni}_{6} \mathrm{MnO}_{8}$ catalyst. Note that ultrathin Au-NWs are an active component for ORRs, and their activity is higher than those of previously reported Au-based catalysts (Table S2). To probe the effect of $\mathrm{Au}-\mathrm{NW}$ s on ORR performance, the $\mathrm{Ni}_{6} \mathrm{MnO}_{8}$-supported $\mathrm{Au}$ nanoparticles (Au-NPs/ $\mathrm{Ni}_{6} \mathrm{MnO}_{8}$ ) were subjected to an ORR test. The detailed characterizations of $\mathrm{Au}-\mathrm{NPs} / \mathrm{Ni}_{6} \mathrm{MnO}_{8}$ are presented in Fig. S12. Au-NPs $/ \mathrm{Ni}_{6} \mathrm{MnO}_{8}$ exhibited inferior ORR activity in comparison to the $\mathrm{Au}-\mathrm{NW} / \mathrm{Ni}_{6} \mathrm{MnO}_{8}$ catalyst (Fig. S13), further verifying that the anisotropically ultrathin 1D nanostructure accounts for the high ORR activity of Au-NWs/ $/ \mathrm{Ni}_{6} \mathrm{MnO}_{8}$. The anisotropic 1D nanowires possess many exposed surface atoms that can work as high-efficiency active sites, thus elevating the atom utilization efficiency of the catalysts ${ }^{45,46} \cdot \mathrm{Ni}_{6} \mathrm{MnO}_{8}$ microspheres can act as a support and promoter to facilitate ORRs, due to their unique 3D hierarchically porous structure. Additionally, the Mn (IV) sites from $\mathrm{Ni}_{6} \mathrm{MnO}_{8}$ oxide for the enhanced ORR activity cannot be neglected. This is because Mn (IV) cations can effectively assist the charge transfer to adsorb oxygen on the catalyst surface, facilitating $\mathrm{HO}_{2}{ }^{-}$decomposition ${ }^{47,48}$. Thus, the strong incorporation of Au-NWs with $\mathrm{Ni}_{6} \mathrm{MnO}_{8}$ (i.e., synergistic effect) makes hybridization a very promising ORR catalyst, even better than the commercial $\mathrm{Pt} / \mathrm{C}$ catalyst (Fig. 4a). As Table S3 lists, the Au-NWs $/ \mathrm{Ni}_{6} \mathrm{MnO}_{8}$ catalyst is also more active than the reported ORR catalysts. Additionally, Au-NWs $/ \mathrm{Ni}_{6} \mathrm{MnO}_{8}$ has a smaller Tafel slope of $62 \mathrm{mVDec}^{-1}$ (Fig. S14) than that of Au-NWs $\left(63 \mathrm{mV} \mathrm{Dec}^{-1}\right), \mathrm{Ni}_{6} \mathrm{MnO}_{8}\left(140 \mathrm{mV} \mathrm{Dec}^{-1}\right)$, and commercial Pt/C (74 $\left.\mathrm{mV} \mathrm{Dec}^{-1}\right)$, indicating a better kinetic process. To quantify the catalysts' ORR efficiencies, RRDE measurements were employed. Within a wide potential range $(0.4-0.8 \mathrm{~V})$, the average electron transfer number (n) and $\mathrm{HO}_{2}{ }^{-}$yield for $\mathrm{Au}-\mathrm{NW} / \mathrm{Ni}_{6} \mathrm{MnO}_{8}$ are ca. 3.85 and $7.47 \%$ (Fig. $4 \mathrm{~b}$ and Fig. S15), respectively, which are obviously superior to those for the $\mathrm{Ni}_{6} \mathrm{MnO}_{8}$ sample (2.74
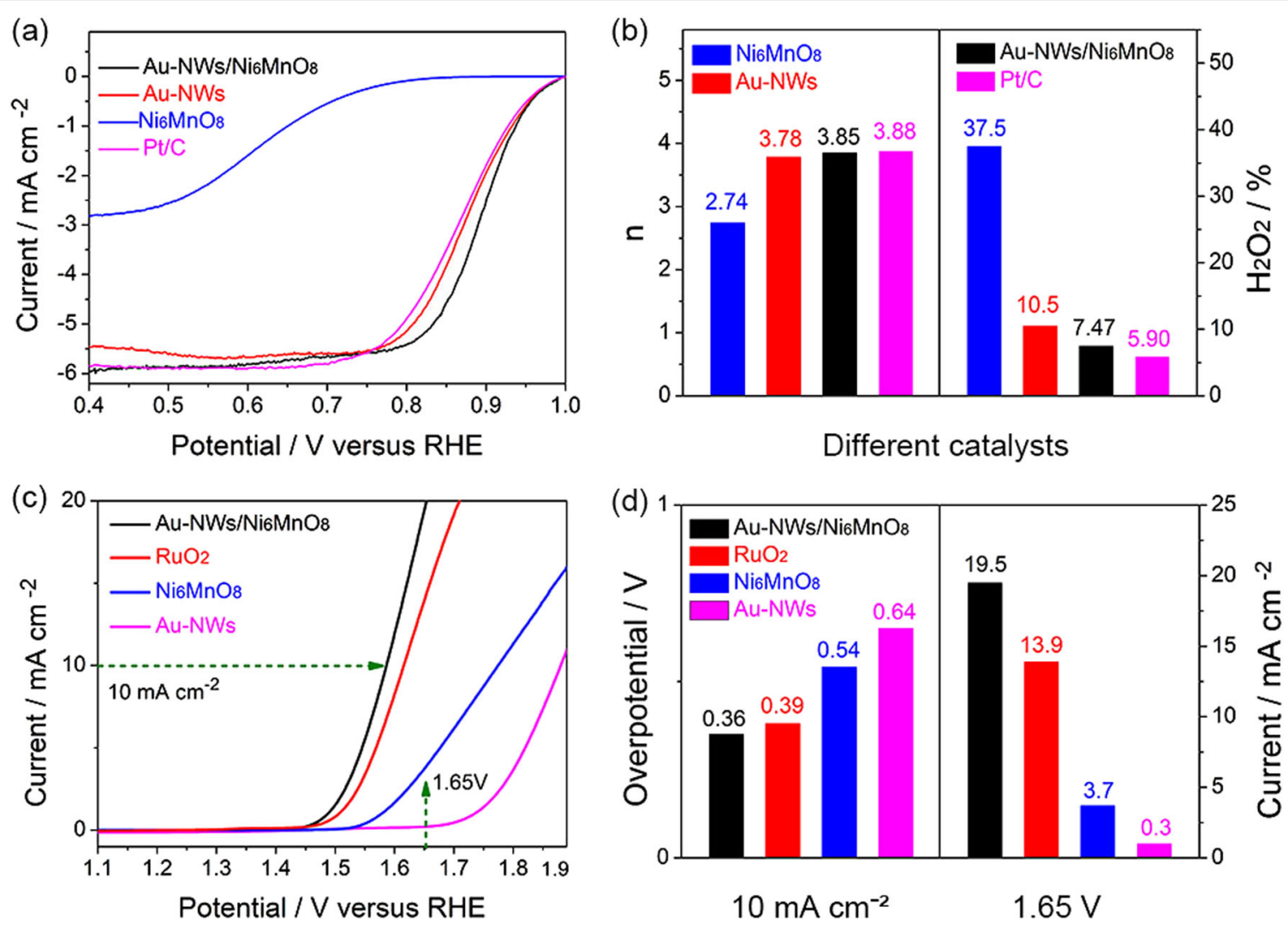

Fig. 4 a ORR polarization curves of catalysts in $\mathrm{O}_{2}$-saturated $0.1 \mathrm{M} \mathrm{KOH}$ (rotation rate: $1600 \mathrm{rpm}$; sweep rate: $5 \mathrm{mV} \mathrm{s}^{-1}$ ); $\mathbf{b}$ bar plots of the electron transfer number and percentage of peroxide; c OER polarization curves of the catalysts in $\mathrm{O}_{2}$-saturated $0.1 \mathrm{M} \mathrm{KOH}$ (rotation rate: 1600 rpm; sweep rate: $5 \mathrm{mV} \mathrm{s}^{-1}$ ); $\mathbf{d}$ bar plots of the $E_{\text {onset }}$ and $E_{1 / 2}$ 
and $37.5 \%)$. This fact further indicates that Au nanowire is a favorable conductive electronic network $(n: 3.78$ and $\mathrm{HO}_{2}{ }^{-}$yield: $10.5 \%$ ). These values are very similar to those for the commercial $\mathrm{Pt} / \mathrm{C}$ catalyst (3.88 and 5.90\%), indicating a good four-electron ORR pathway for the $\mathrm{Au}$ $\mathrm{NWs} / \mathrm{Ni}_{6} \mathrm{MnO}_{8}$ catalyst.

Apart from the remarkable ORR activity, the Au-NWs/ $\mathrm{Ni}_{6} \mathrm{MnO}_{8}$ catalyst also has very good OER activity. Figure 4c shows the OER polarization curves for Au-NWs/ $\mathrm{Ni}_{6} \mathrm{MnO}_{8}$ and other samples. Clearly, the Au-NWs/ $\mathrm{Ni}_{6} \mathrm{MnO}_{8}$ catalyst exhibits a lower overpotential and a higher current density over the provided potential range compared to the other references (Fig. 4d). At the current density of $10 \mathrm{~mA} \mathrm{~cm}{ }^{-2}$, Au-NWs $/ \mathrm{Ni}_{6} \mathrm{MnO}_{8}$ has a very low overpotential $\left(E_{\mathrm{J} 10}\right)$ of $0.36 \mathrm{~V}$, outperforming the state-of-the-art $\mathrm{RuO}_{2}$ catalyst $(0.39 \mathrm{~V})$, and is even comparable to those of other non-noble metal catalysts (Table S4). Pure Au-NWs show a poor OER response, indicating that unsupported Au-NWs do not work as an active catalytic site for the OER. The excellent OER activity of Au-NWs/ $\mathrm{Ni}_{6} \mathrm{MnO}_{8}$ probably principally arise from the intrinsic OER property of $\mathrm{Ni}_{6} \mathrm{MnO}_{8}$, as indicated by the lower onset-potential compared with that of $\mathrm{Au}$ NWs. As shown in Fig. S16, the Tafel plots for the OER of
$\mathrm{Au}-\mathrm{NWs} / \mathrm{Ni}_{6} \mathrm{MnO}_{8}$ exhibit a slope of $62 \mathrm{mV} \mathrm{Dec}^{-1}$, lower than that of the Au-NW $\left(101 \mathrm{mVDec}^{-1}\right), \mathrm{Ni}_{6} \mathrm{MnO}_{8}$ $\left(82 \mathrm{mV} \mathrm{Dec}^{-1}\right)$, and $\mathrm{RuO}_{2}\left(76 \mathrm{mV} \mathrm{Dec}^{-1}\right)$ catalysts. To further explore the active site of $\mathrm{Ni}_{6} \mathrm{MnO}_{8}$ for OERs, we performed a theoretical investigation by calculating the free energies based on density functional theory. Figure 5 compares how the free energy of OER changes at the $\mathrm{Ni}$ sites (Fig. 5a) and the Mn sites (Fig. 5b) of $\mathrm{Ni}_{6} \mathrm{MnO}_{8}$. Generally, OERs abide by the following four-electron step process:

$$
\begin{aligned}
& \mathrm{OH}^{-}+{ }^{*} \rightarrow \mathrm{HO}^{*}+e^{-} \\
& \mathrm{HO}^{*}+\mathrm{OH}^{-} \rightarrow \mathrm{H}_{2} \mathrm{O}+\mathrm{O}^{*}+e^{-} \\
& \mathrm{O}^{*}+\mathrm{OH}^{-} \rightarrow \mathrm{HOO}^{*}+e^{-} \\
& \mathrm{HOO}^{*}+\mathrm{OH}^{-} \rightarrow \mathrm{O}_{2}^{*}+e^{-}
\end{aligned}
$$

It is seen that all the elementary reactions are positive free energy change (endothermic) at zero electrode potential. As the electrode potential increases to the equilibrium potential at $1.23 \mathrm{~V}$, some elementary reactions (e.g., $\mathrm{OH}^{*}$ and $\mathrm{O}^{*}$ formation) become energetically downhill (exothermic). All the elementary reactions become downhill until the electrode potential increases to $2.13 \mathrm{~V}$ for the $\mathrm{Ni}$ sites and $2.48 \mathrm{~V}$ for the $\mathrm{Mn}$ sites on the $\mathrm{Ni}_{6} \mathrm{MnO}_{8}$ surface. This fact suggests the overpotential is

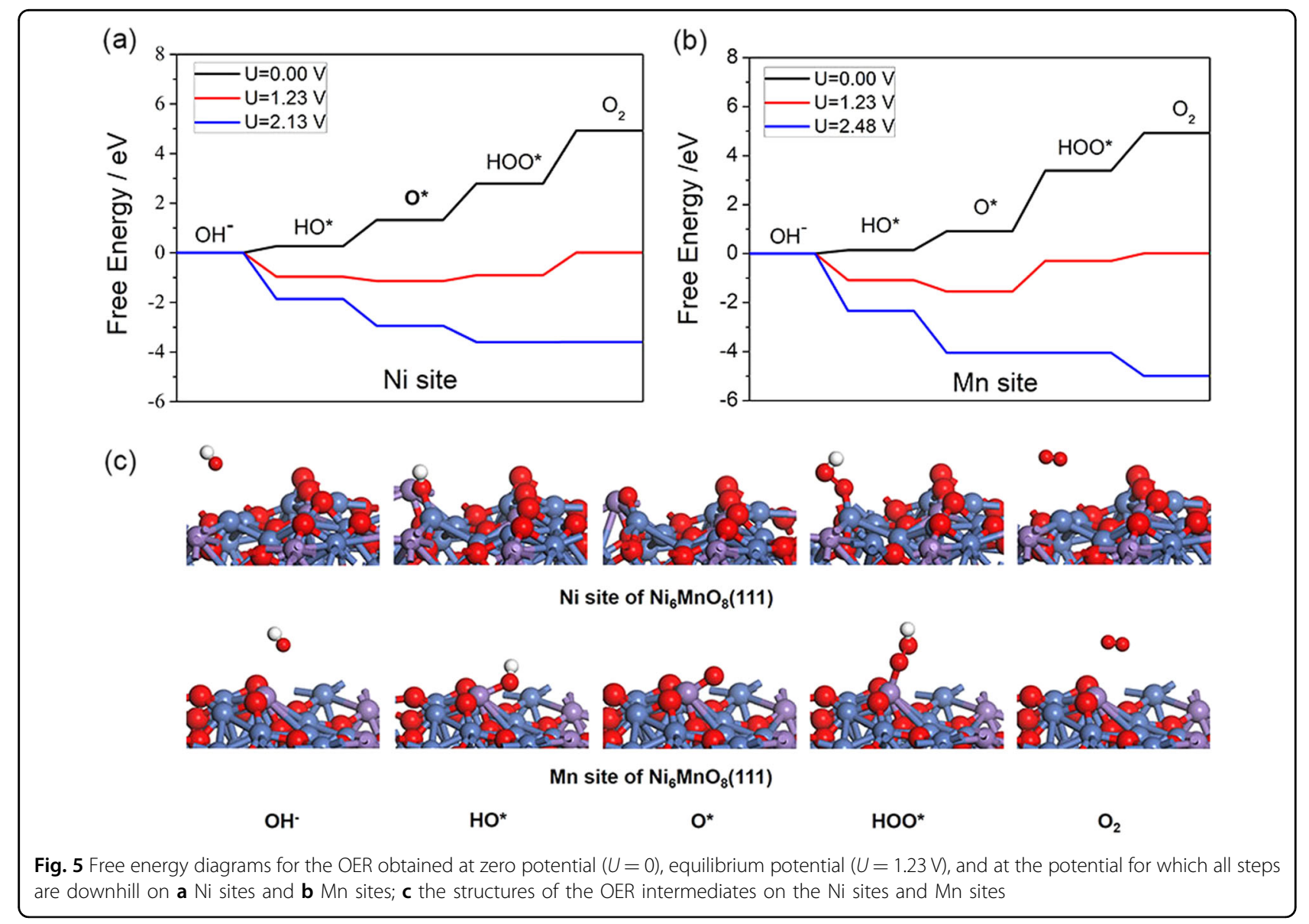



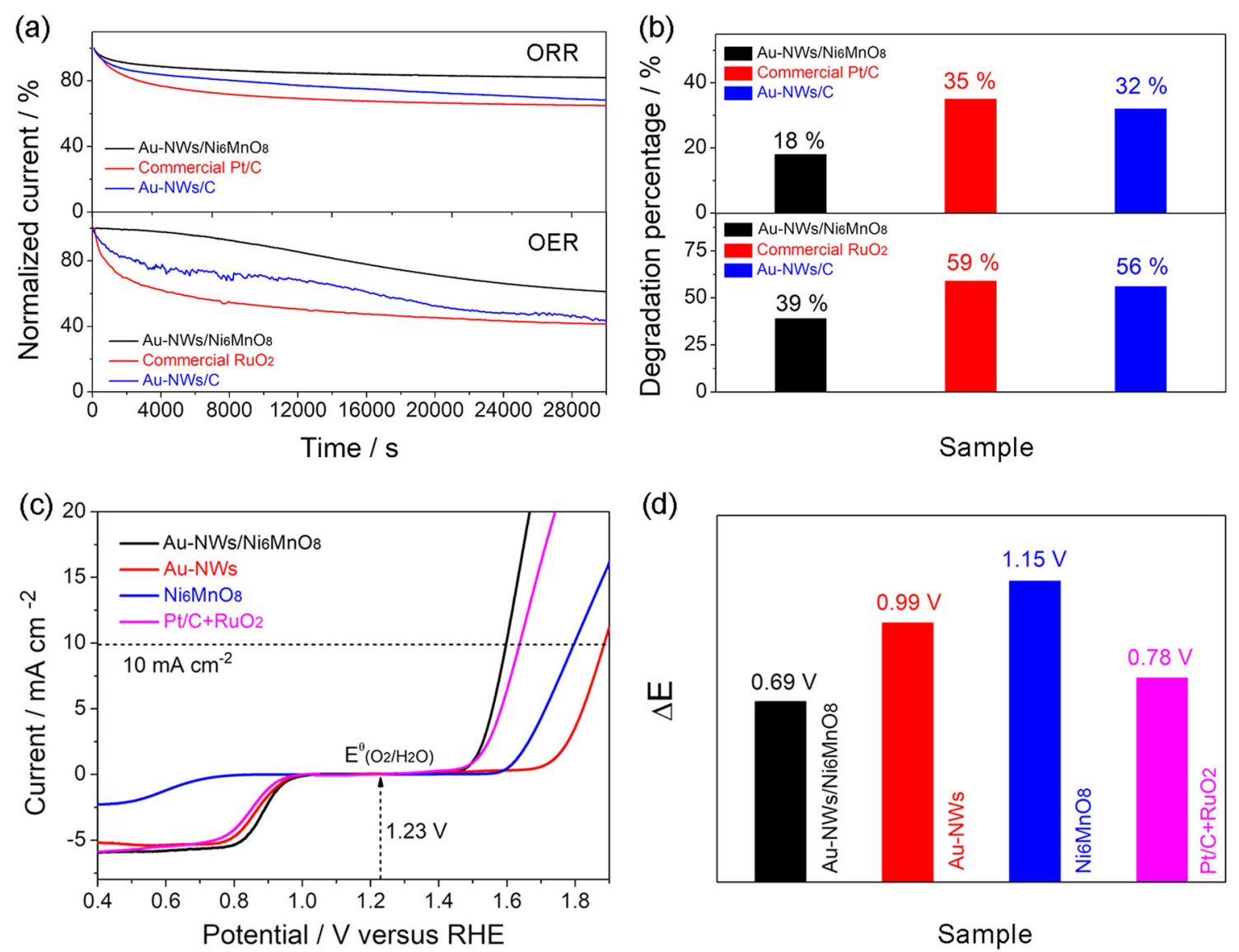

Fig. 6 a Current-time chronoamperometric responses for the ORR at $0.75 \mathrm{~V}$ and the OER at $1.60 \mathrm{~V}$ (percentage of current retained vs. operation time); b bar plots of the degradation percentage of the catalysts for the ORR (top panel) and the OER (bottom panel) after the stability tests; $\mathbf{c}$ the overall polarization curves of $\mathrm{Au}-\mathrm{NW} s / \mathrm{Ni}_{6} \mathrm{MnO}_{8}, \mathrm{Au}-\mathrm{NW}, \mathrm{Ni}_{6} \mathrm{MnO}_{8}$, and $\mathrm{Pt} / \mathrm{C}+\mathrm{RuO}_{2}$ catalysts; $\mathbf{d}$ the oxygen electrode activity was evaluated by the difference in the potential between the OER current density at $10 \mathrm{~mA} \mathrm{~cm}^{-2}$ and the ORR current density at the half-wave potential $\left(\Delta E=E_{110}-E_{1 / 2}\right)$

0.90 and $1.25 \mathrm{~V}$ on the $\mathrm{Ni}$ sites and Mn sites. It can be concluded that the overpotential on the Ni sites is lower than that on the Mn sites, indicating that the Ni sites have superior OER activity and are the preferred reaction active sites. Figure $5 \mathrm{c}$ shows the corresponding structures of OER intermediates on the $\mathrm{Ni}$ sites and $\mathrm{Mn}$ sites of $\mathrm{Ni}_{6} \mathrm{MnO}_{8}$.

Notably, $\mathrm{Ni}_{6} \mathrm{MnO}_{8}$ alone cannot explain such a good OER activity of the Au-NWs $/ \mathrm{Ni}_{6} \mathrm{MnO}_{8}$ catalyst, which arises from its poor electrical conductivity. Previous studies demonstrated that some hydroxides, including $\mathrm{NiFeOOH}, \mathrm{NiOOH}$, and $\mathrm{CoOOH}$, have better OER activities on a $\mathrm{Au}$ substrate than on glassy carbon; this phenomenon was attributed to the partial electron transfer from hydroxides to more electronegative $\mathrm{Au}^{49,50}$. It is therefore reasonable to infer that Au-NWs improve the electrical conductivity of the catalytic active centers in $\mathrm{Ni}_{6} \mathrm{MnO}_{8}$ due to the difference of the work functions and the strong interfacial coupling between $\mathrm{Au}-\mathrm{NWs}$ and $\mathrm{Ni}_{6} \mathrm{MnO}_{8}$. The results demonstrate the advantages of the strongly coupled Au-NWs and $\mathrm{Ni}_{6} \mathrm{MnO}_{8}$ at boosting bifunctional oxygen electrocatalysis: Au-NWs bring both catalytic active sites for the ORR and a high electrical conductivity, which facilitates electron transport during electrocatalysis, whereas $\mathrm{Ni}_{6} \mathrm{MnO}_{8}$ is catalytically active for the OER due to its intrinsic OER property and improves mass transport by the 3D hierarchically porous structure. The stability of $\mathrm{Au}-\mathrm{NWs} / \mathrm{Ni}_{6} \mathrm{MnO}_{8}$ as a bifunctional catalyst was investigated for the ORR and the OER using the chronoamperometric method (Fig. 6a). $\mathrm{Au}-\mathrm{NWs} / \mathrm{Ni}_{6} \mathrm{MnO}_{8}$ shows better electrocatalytic stabilities during both the OER and ORR than those of the commercial $\mathrm{Pt} / \mathrm{C}$ and $\mathrm{RuO}_{2}$ catalysts after $30,000 \mathrm{~s}$ (Fig. 6b). More importantly, the $\mathrm{Ni}_{6} \mathrm{MnO}_{8}$-supported $\mathrm{Au}$ NWs clearly improved the stability relative to that of the $\mathrm{Au}-\mathrm{NWs} / \mathrm{C}$ catalyst, which apparently arises from the preferable chemical stability and structural stability of $\mathrm{Ni}_{6} \mathrm{MnO}_{8}$. A favorable chemical stability would be beneficial to the electrochemical stability of catalysts ${ }^{43}$. When cycling repeatedly at a wide potential range of ORRs and 


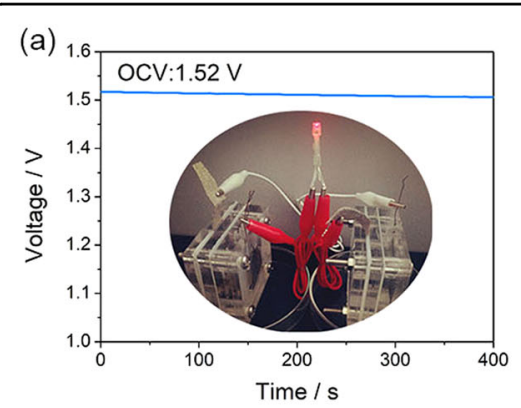

(d)

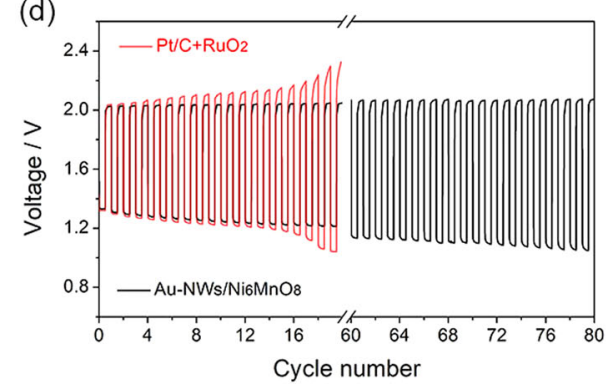

(b)

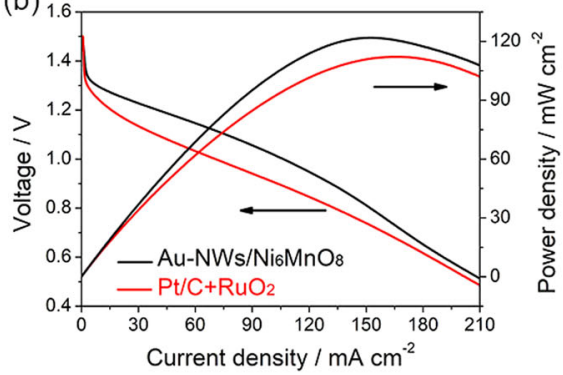

(e)

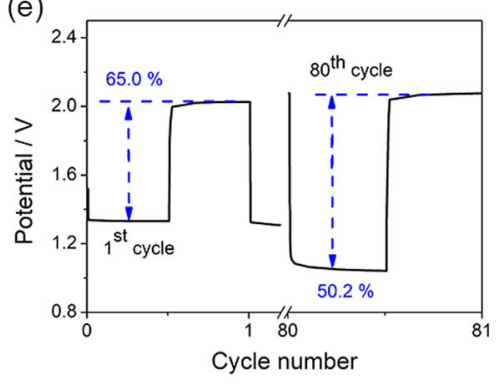

(c) 1

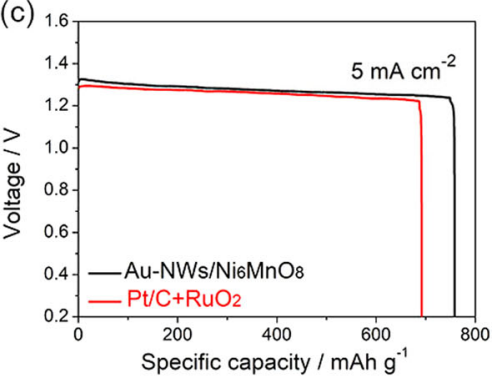

(f)

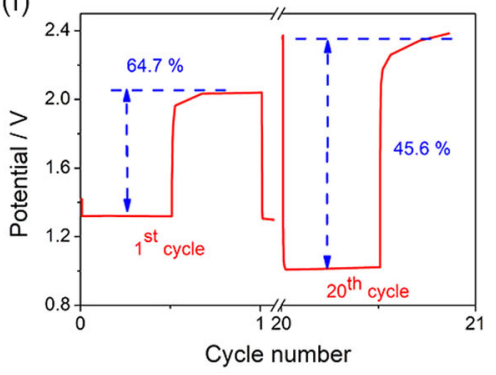

Fig. 7 a Open-circuit plots, the inset shows the photograph of a red LED powered by two home-made Zn-air batteries in series with Au-NWs/ $\mathrm{Ni}_{6} \mathrm{MnO}_{8}$ as the air-cathode; $\mathbf{b}$ discharge polarization and power density curves; $\mathbf{c}$ discharge curves of $\mathrm{Zn}$-air batteries at $5 \mathrm{~mA} \mathrm{~cm}{ }^{-2} ; \mathbf{d}$ long-term cycling performance at the charging and discharging current density of $10 \mathrm{~mA} \mathrm{~cm}{ }^{-2}$. The enlarged 1st and last cycle discharge and charge voltage profiles of $\mathrm{Zn}$-air batteries with $\mathbf{e}$ the $\mathrm{Au}-\mathrm{NWs} / \mathrm{Au}_{6} \mathrm{MnO}_{8}$ catalyst and $\mathbf{f}$ the $\mathrm{Pt} / \mathrm{C}+\mathrm{RuO} \mathrm{O}_{2}$ catalyst

OERs for 100 cycles at $0.1 \mathrm{M} \mathrm{KOH}$ (Fig. S17), there was no observable degradation of the electrochemical signal associated with $\mathrm{Ni}_{6} \mathrm{MnO}_{8}$, demonstrating that $\mathrm{Ni}_{6} \mathrm{MnO}_{8}$ is electrochemically stable. Furthermore, 1D Au-NWs within the 3D hierarchically porous architecture impede agglomeration and dissolution of catalyst particles. The remarkable electrocatalytic activity and stability of $\mathrm{Au}-$ $\mathrm{NWs} / \mathrm{Ni}_{6} \mathrm{MnO}_{8}$ make it highly promising as a bifunctional oxygen catalyst, as further indicated by the overall oxygen electrode curves (Fig. 6c, d). The oxygen electrode activity $\left(\Delta E=E_{\mathrm{J} 10}-E_{1 / 2}\right)$ of Au-NWs/ $\mathrm{Ni}_{6} \mathrm{MnO}_{8}$ noticeably present the smallest value $(0.69 \mathrm{~V})$ of all the provided catalysts and is even comparable with that of other reported bifunctional electrocatalysts (Table S5), confirming that the Au-NWs/ $/ \mathrm{Ni}_{6} \mathrm{MnO}_{8}$ catalyst is one of the most efficient bifunctional catalysts.

\section{Rechargeable $\mathbf{Z n}$-air batteries}

Using the prominent bifunctional performance of the $\mathrm{Au}-\mathrm{NW} / \mathrm{Ni}_{6} \mathrm{MnO}_{8}$ hybrid, a $\mathrm{Zn}$-air battery was designed and assembled to evaluate its feasibility, as exhibited in Fig. S18. The open-circuit voltage (OCV) of the Au-NWs/ $\mathrm{Ni}_{6} \mathrm{MnO}_{8}$-driven $\mathrm{Zn}$-air battery is approximately $1.52 \mathrm{~V}$ (Fig. 7a), which is in the vicinity of the theoretical voltage $(1.65 \mathrm{~V})$. Two cells connected in series can work as an efficient energy supplier to power a red light-emitting diode (LED, 3.0 V). For comparison, a mixed Pt/C $+\mathrm{RuO}_{2}$ catalyst (the mass ratio of $\mathrm{Pt} / \mathrm{C}$ and $\mathrm{RuO}_{2}$ was of $1 / 1$ ) was also tested as a control air-cathode. Figure $7 \mathrm{~b}$ shows the discharge polarization curves and the corresponding power density curves. Au-NWs $/ \mathrm{Ni}_{6} \mathrm{MnO}_{8}$ exhibits a decent current density of $104.9 \mathrm{~mA} \mathrm{~cm}^{-2}$ at $1.0 \mathrm{~V}$, which is superior to that of the mixed $\mathrm{Pt} / \mathrm{C}+\mathrm{RuO}_{2}$ catalyst $\left(70.2 \mathrm{~mA} \mathrm{~cm}^{-2}\right)$. The maximum power density of ca. $121 \mathrm{~mW} \mathrm{~cm}^{-2}$ exceeds that of the battery with $\mathrm{Pt} / \mathrm{C}+$ $\mathrm{RuO}_{2}\left(110 \mathrm{~mW} \mathrm{~cm}{ }^{-2}\right)$ and many other reported bifunctional catalysts (Table S6). The specific capacity of the Au$\mathrm{NWs} / \mathrm{Ni}_{6} \mathrm{MnO}_{8}$-based battery was up to $760 \mathrm{mAh} \mathrm{ZZn}^{-1}$ at a current density of $5 \mathrm{~mA} \mathrm{~cm}^{-2}$ (Fig. 7c), corresponding to an energy density of $996 \mathrm{Wh} \mathrm{kg}_{\mathrm{Zn}}{ }^{-1}$, which surpasses those of $\mathrm{Pt} / \mathrm{C}+\mathrm{RuO}_{2}\left(692 \mathrm{mAh} \mathrm{g}_{\mathrm{Zn}}{ }^{-1} ; 892 \mathrm{Wh} \mathrm{kg}_{\mathrm{Zn}}{ }^{-1}\right)$ and previously reported state-of-the-art air-cathodes (Table S7). Moreover, the $\mathrm{Au}-\mathrm{NW} / \mathrm{Ni}_{6} \mathrm{MnO}_{8}$-based battery demonstrated superior cycle stability compared to that of the mixed $\mathrm{Pt} / \mathrm{C}+\mathrm{RuO}_{2}$ catalyst (Fig. $7 \mathrm{~d}$ ). For instance, the 1st cycle discharge-charge voltage gap is only $0.70 \mathrm{~V}$, contributing to a high energy efficiency of $65 \%$. After 80 cycles, both the voltage gap and the energy efficiency remain at high values, $1.02 \mathrm{~V}$ and $50.2 \%$ (Fig. 7e), respectively. Comparatively, the $\mathrm{Pt} / \mathrm{C}+\mathrm{RuO}_{2}$ based battery has a poor cycle life with a large overpotential increase after 20 cycles (Fig. 7f). After the charge/discharge cycles, the overall morphology and structure of the Au-NWs/ $/ \mathrm{Ni}_{6} \mathrm{MnO}_{8}$ cathode material were well preserved (Fig. S19). These results verify the excellent activity and stability of the $\mathrm{Au}-\mathrm{NWs} / \mathrm{Au}_{6} \mathrm{MnO}_{8}$ catalyst as the air-cathode in rechargeable $\mathrm{Zn}$-air batteries. 


\section{Discussion}

In summary, we have developed a simple and efficient strategy for the synthesis of a strongly coupled Au-NWs/ $\mathrm{Ni}_{6} \mathrm{MnO}_{8}$ material with both rigidity and flexibility as a new, low-cost, and highly active air-cathode for rechargeable $\mathrm{Zn}$-air batteries. The $\alpha$-naphthol-Au(III) complex plays a critical role in regulating the morphology of $\mathrm{Au}$ nanocrystals and synthesizing $\mathrm{Ni}_{6} \mathrm{MnO}_{8}$-supported $\mathrm{Au}$ nanowires. The synergistical integration of $\mathrm{Ni}_{6} \mathrm{MnO}_{8}$ that is active for OERs and $\mathrm{Au}$ nanowires that are active for ORRs endows the hybrid with a superior bifunctional electrocatalytic performance. The rigid $\mathrm{Ni}_{6} \mathrm{MnO}_{8}$ also makes the electrochemical properties more stable over the potential range of an air-cathode in an alkaline media, while the flexible $\mathrm{Au}$ nanowires offer effective electron transport channels as conductive bridges. The strong cross-link between the hierarchically porous $\mathrm{Ni}_{6} \mathrm{MnO}_{8}$ and $\mathrm{Au}$ nanowires provides an additional synergistic effect to further enhance electrocatalytic activity and stability, by virtue of its unique structural advantages. Moreover, the $\mathrm{Au}-\mathrm{NWs} / \mathrm{Ni}_{6} \mathrm{MnO}_{8}$-driven $\mathrm{Zn}$-air battery can output a high OCV of $1.52 \mathrm{~V}$, a high peak power density of $118 \mathrm{~mW} \mathrm{~cm}^{-2}$, and a large specific capacity of $768 \mathrm{mAh}_{\mathrm{Zn}}{ }^{-1}$. This work offers an innovative strategy for developing carbon-free bifunctional electrocatalysts that have many potential applications in metal-air batteries.

\footnotetext{
Acknowledgements

This work was financially supported by the National Natural Science Foundation of China (NSFC Nos. 21576139 and 21503111), the Natural Science Foundation of Jiangsu Province (BK20171473), the Natural Science Foundation of Jiangsu Higher Education Institutions of China (16KJB150020), and the National and Local Joint Engineering Research Center of Biomedical Functional Materials and Priority Academic Program Development of Jiangsu Higher Education Institutions.
}

\section{Conflict of interest}

The authors declare that they have no conflict of interest.

\section{Publisher's note}

Springer Nature remains neutral with regard to jurisdictional claims in published maps and institutional affiliations.

Supplementary Information is available for this paper at https://doi.org/ 10.1038/s41427-018-0057-y.

Received: 22 January 2018 Revised: 16 April 2018 Accepted: 15 May 2018. Published online: 11 July 2018

\section{References}

1. Zhong, $\mathrm{H}$. X. et al. In situ anchoring of $\mathrm{CO}_{9} \mathrm{~S}_{8}$ nanoparticles on $\mathrm{N}$ and $\mathrm{S}$ codoped porous carbon tube as bifunctional oxygen electrocatalysts. NPG Asia Mater. 8, e308 (2016).

2. Tang, C., Wang, B., Wang, H. F. \& Zhang, Q. Defect engineering toward atomic $\mathrm{Co}-\mathrm{N}_{\mathrm{x}}-\mathrm{C}$ in hierarchical graphene for rechargeable flexible solid $\mathrm{Zn}$-air batteries. Adv. Mater. 29, 1703185 (2017).

3. Fu, G., Tang, Y. \& Lee, J.-M. Recent advances in carbon-based bifunctional oxygen electrocatalysts for Zn-air batteries. ChemElectroChem. 5, 1424-1434 (2018).
4. Wang, Q. et al. NiFe layered double hydroxide nanoparticles on Co,Ncodoped carbon nanoframes as efficient bifunctional catalysts for rechargeable zinc-air batteries. Adv. Energy Mater. 7, 1700467 (2017).

5. Wang, H.-F., Tang, C., Wang, B., Li, B.-Q. \& Zhang, Q. Bifunctional transition metal hydroxysulfides: room-temperature sulfurization and their applications in Zn-air batteries. Adv. Mater. 29, 1702327 (2017).

6. Yin, J. et al. NiO/CoN porous nanowires as efficient bifunctional catalysts for Zn-air batteries. ACS Nano 11, 2275-2283 (2017).

7. Park, J., Park, M., Nam, G., Kim, M. G. \& Cho, J. Unveiling the catalytic origin of nanocrystalline yttrium ruthenate pyrochlore as a bi-functional electrocatalyst for Zn-air batteries. Nano Lett. 17, 3974-3981 (2017).

8. Qu, K., Zheng, Y., Dai, S. \& Qiao, S. Z. Graphene oxide-polydopamine derived N, S-codoped carbon nanosheets as superior bifunctional electrocatalysts for oxygen reduction and evolution. Nano Energy 19, 373-381 (2016).

9. Liu, Q., Wang, Y., Dai, L. \& Yao, J. Scalable fabrication of nanoporous carbon fiber films as bifunctional catalytic electrodes for flexible $\mathrm{Zn}$-air batteries. Adv. Mater. 28, 3000-3006 (2016).

10. Fu, J. et al. Electrically rechargeable zinc-air batteries: progress, challenges, and perspectives. Adv. Mater. 29, 1604685 (2017).

11. Lee, D. U. et al. Recent progress and perspectives on bi-functional oxygen electrocatalysts for advanced rechargeable metal-air batteries. J. Mater. Chem. A 4, 7107-7134 (2016).

12. Narayan, S. R., Manohar, A. K. \& Mukerjee, S. Bi-functional oxygen electrodeschallenges and prospects. Electrochem. Soc. Int. 24, 65-69 (2015).

13. Ahn, S. H. \& Manthiram, A. Cobalt phosphide coupled with heteroatom-doped nanocarbon hybrid electroctalysts for efficient, long-life rechargeable zinc-air batteries. Small 13, 1702068 (2017).

14. Yang, D., Zhang, L., Yan, X. \& Yao, X. Recent progress in oxygen electrocatalysts for zinc-air batteries. Small Methods 1, 1700209 (2017).

15. Zhang, J., Zhao, Z., Xia, Z. \& Dai, L. A metal-free bifunctional electrocatalyst for oxygen reduction and oxygen evolution reactions. Nat. Nanotechnol. 10, 444-452 (2015).

16. Li, G. et al. Pomegranate-inspired design of highly active and durable bifunctional electrocatalysts for rechargeable metal-air batteries. Angew. Chem. Int. Ed. 55, 4977-4982 (2016).

17. Yang, H. B. et al. Identification of catalytic sites for oxygen reduction and oxygen evolution in $\mathrm{N}$-doped graphene materials: development of highly efficient metal-free bifunctional electrocatalyst. Sci. Adv. 2, 1501122 (2016).

18. Park, M. G., Lee, D. U., Seo, M. H., Cano, Z. P. \& Chen, Z. 3D ordered mesoporous bifunctional oxygen catalyst for electrically rechargeable zinc-air batteries. Small 12, 2707-2714 (2016).

19. An, L. et al. Atomic-level coupled interfaces and lattice distortion on CuS/NiS nanocrystals boost oxygen catalysis for flexible $\mathrm{Zn}$-air batteries. Adv. Funct. Mater. 12, 1703779 (2017).

20. Fu, G. et al. Boosting bifunctional oxygen electrocatalysis with 3D graphene aerogel-supported Ni/MnO particles. Adv. Mater. 30, 1704609 (2018).

21. $\mathrm{Fu}, \mathrm{J}$. et al. Defect engineering of chalcogen-tailored oxygen electrocatalysts for rechargeable quasi-solid-state zinc-air batteries. Adv. Mater. 29, 1702526 (2017).

22. $\mathrm{Fu}, \mathrm{G}$. et al. Novel hydrogel-derived bifunctional oxygen electrocatalyst for rechargeable air cathodes. Nano Lett. 16, 6516-6522 (2016).

23. Liu, S. et al. Metal-organic-framework-derived hybrid carbon nanocages as a bifunctional electrocatalyst for oxygen reduction and evolution. Adv. Mater. 29 1700874 (2017).

24. Yamada, I. et al. Bifunctional oxygen reaction catalysis of quadruple manganese perovskites. Adv. Mater. 29, 1603004 (2017)

25. Cheng, H., Li, M.-L., Su, C.-Y., Li, N. \& Liu, Z.-Q. Cu-Co bimetallic oxide quantum dot decorated nitrogen-doped carbon nanotubes: a high-efficiency bifunctional oxygen electrode for Zn-air batteries. Adv. Funct. Mater. 27, 1701833 (2017).

26. Liu, Z. Q., Cheng, H., Li, N., Ma, T. Y. \& Su, Y.-Z. $\mathrm{ZnCO}_{2} \mathrm{O}_{4}$ quantum dots anchored on nitrogen-doped carbon nanotubes as reversible oxygen reduction/evolution electrocatalysts. Adv. Mater. 28, 3777-3784 (2016).

27. Park, J. et al. Single crystalline pyrochlore nanoparticles with metallic conduction as efficient bi-functional oxygen electrocatalysts for Zn-air batteries. Energy Environ. Sci. 10, 129-136 (2017).

28. Li, G. et al. Pomegranate-inspired design of highly active and durable bifunctional electrocatalysts for rechargeable metal-air batteries. Angew. Chem. Int. Ed. 55, 4977-4982 (2016).

29. Gao, Y., Zhao, H., Chen, D. J., Chen, C. \& Ciucci, F. In situ synthesis of mesoporous manganese oxide/sulfur-doped graphitized carbon as a bifunctional 
catalyst for oxygen evolution/reduction reactions. Carbon 94, 1028-1036 (2015).

30. Liu, T. et al. CoO nanoparticles embedded in three-dimensional nitrogen/sulfur co-doped carbon nanofiber networks as a bifunctional catalyst for oxygen reduction/evolution reactions. Carbon 106, 84-92 (2016).

31. Hao, Y. C., Xu, Y. Q., Liu, J. F. \& Sun, X. M. Nickel-cobalt oxides supported on Co/ $\mathrm{N}$ decorated graphene as an excellent bifunctional oxygen catalyst. J. Mater. Chem. A 5, 5594-5600 (2017)

32. Liu, S. Y., Li, L. J., Ahnb, H. S. \& Manthiram, A. Delineating the roles of $\mathrm{Co}_{3} \mathrm{O}_{4}$ and $\mathrm{N}$-doped carbon nanoweb (CNW) in bifunctional $\mathrm{CO}_{3} \mathrm{O}_{4} / \mathrm{CNW}$ catalysts for oxygen reduction and oxygen evolution reactions. J. Mater. Chem. A $\mathbf{3}$, 11615-11623 (2015)

33. Park, H. W. et al. Electrospun porous nanorod perovskite oxide/nitrogendoped graphene composite as a bi-functional catalyst for metal air batteries. Nano Energy 10, 192-200 (2014).

34. Prabu, M., Ramakrishnan, P., Ganesan, P., Manthiram, A. \& Shanmugam, S. $\mathrm{LaTi}_{0.65} \mathrm{Fe}_{0.35} \mathrm{O}_{3}$-delta nanoparticle-decorated nitrogen-doped carbon nanorods as an advanced hierarchical air electrode for rechargeable metal-air batteries. Nano Energy 15, 92-103 (2015).

35. Liang, $\mathrm{Y}$. Y. et al. $\mathrm{CO}_{3} \mathrm{O}_{4}$ nanocrystals on graphene as a synergistic catalyst for oxygen reduction reaction. Nat. Mater. 10, 780-786 (2011).

36. Cui, Z., Fu, G., Li, Y. \& Goodenough, J. B. Ni ${ }_{3} F e N$ supported Fe ${ }_{3}$ Pt intermetallic nanoalloy as a high performance bifunctional catalyst for metal-air battery. Angew. Chem. Int. Ed. 56, 9901-9905 (2017).

37. Parrondo, J. et al. Platinum supported on titanium-ruthenium oxide is a remarkably stable electrocatayst for hydrogen fuel cell vehicles. Proc. Natl. Acad. Sci. USA 111, 45-50 (2014).

38. Alegre, C. et al. Pd supported on Ti-suboxides as bifunctional catalyst for air electrodes of metal-air batteries. Int. J. Hydrog. Energy 41, 19579-19586 (2016).
39. Han, X. P. et al. Hydrogenated uniform Pt clusters supported on porous $\mathrm{CaMnO}_{3}$ as a bifunctional electrocatalyst for enhanced oxygen reduction and evolution. Adv. Mater. 26, 2047-2051 (2014).

40. Amin, H. M. A., Baltruschat, H., Wittmaier, D. \& Friedrich, K. A. A highly efficient bifunctional catalyst for alkaline air-electrodes based on a $\mathrm{Ag}$ and $\mathrm{CO}_{3} \mathrm{O}_{4}$ hybrid: RRDE and online DEMS insights. Electrochim. Acta 151, 332-339 (2015).

41. Porta, P., Minelli, G., Botto, I. L. \& Baran, E. J. Structural, magnetic, and optical investigation of $\mathrm{Ni}_{6} \mathrm{MnO}_{8}$. J. Solid State Chem. 92, 202-207 (1991).

42. Taguchi, H., Omori, S., Nagao, M., Kido, H. \& Shimada, M. Crystal structure and magnetic properties of $\left(\mathrm{Ni}_{1-x} \mathrm{Mg}_{\times}\right)_{6} \mathrm{MnO}_{8}$. J. Solid State Chem. 118, 112-116 (1995).

43. Fu, G. et al. Hierarchically mesoporous nickel-iron nitride as a cost-efficient and highly durable electrocatalyst for Zn-air battery. Nano Energy 39, 77-85 (2017).

44. Liang, J., Jiao, Y., Jaroniec, M. \& Qiao, S. Z. Sulfur and nitrogen dual-doped mesoporous graphene electrocatalyst for oxygen reduction with synergistically enhanced performance. Angew. Chem. Int. Ed. 51, 11496-11500 (2012).

45. Liu, H. et al. In situ probing of the active site geometry of ultrathin nanowires for the oxygen reduction reaction. J. Am. Chem. Soc. 137, 12597-12609 (2015).

46. $\mathrm{Bu}$, L. et al. A general method for multimetallic platinum alloy nanowires as highly active and stable oxygen reduction catalysts. Adv. Mater. 27, 7204-7212 (2015).

47. Rios, E., Gautier, J. L., Poillerat, G. \& Chartier, P. Mixed valency spinel oxides of transition metals and electrocatalysis: case of the $\mathrm{MnxCO}_{3-x} \mathrm{O}_{4}$ system. Electrochim. Acta 44, 1491-1497 (1998).

48. Zhou, H. et al. Studies of decomposition of $\mathrm{H}_{2} \mathrm{O}_{2}$ over manganese oxide octahedral molecular sieve materials. J. Catal. 176, 321-328 (1998).

49. Trotochaud, L., Young, S. L., Ranney, J. K. \& Boettcher, S. W. Nickel-iron oxyhydroxide oxygen-evolution electrocatalysts: the role of intentional and incidental iron incorporation. J. Am. Chem. Soc. 136, 6744-6753 (2014).

50. Yeo, B. S. \& Bell, A. T. Enhanced activity of gold-supported cobalt oxide for the electrochemical evolution of oxygen. J. Am. Chem. Soc. 133, 5587-5593 (2011). 